\title{
KOMUNITAS PENGABDI SENI MUSIK TRADISIONAL KARINDING DI KAMPUNG JAHA TANGERANG
}

\author{
Tyas Siti Nur Asiyah, Musahwi \\ Pendidikan Sosiologi, Fakultas Keguruan dan Ilmu Pendidikan, \\ Universitas Sultan Ageng Tirtayasa \\ tyassitinurasiyah11@gmail.com
}

\begin{abstract}
The existence of music as a representation of traditional culture increasingly doubted by various parties. Especially when he has to deal with international music that has a modern genre. In Indonesia, in line with today's global culture, traditional music is slowly being forgotten. Even considered the music peripheral by his own generation because it is not in line with the latest music trends. Is a community of Barak Karinding that plays traditional musical instruments Karinding typical Sundanese, they try to fight the flow. It is important to be studied with regard to the understanding of Karinding musical art, as well as the social values of humanity (local wisdom) that they stretcher in daily life amid the onslaught of global music products today. The type of this research is qualitative, by trying to describe the phenomenon naturally based on the social setting as it is. The results of this study describes among others: a) Karinding music has value, Belief, Patience, Conscious. As a universal message of their music. b) loving art is loving humanity. That is, musical works are not created for the interests of the market as the mindstream of music today, but to develop constructive human beings.
\end{abstract}

Keywords: traditional music, Karinding, humanity 


\begin{abstract}
Abstrak
Eksistensi seni musik sebagai representasi budaya tradisional semakin diragukan oleh berbagai pihak. Terutama ketika ia harus berhadapan dengan musik internasional yang bergenre modern. Di Indonesia, sejalan dengan budaya global saat ini, musik tradisional pelanpelan mulai dilupakan. Bahkan dinilai musik pinggiran oleh generasinya sendiri karena tidak sejalan dengan tren musik terkini. Adalah komunitas Barak Karinding yang memainkan alat musik tradisional Karinding khas Sunda, mereka berusaha melawan arus tersebut. Hal ini menjadi penting diteliti berkaitan dengan pemahaman kesenian musik Karinding, serta nilainilai sosial kemanusiaan (kearifan lokal) yang mereka usung dalam kehidupan sehari di tengah gempuran produk musik global saat ini. Adapun jenis penelitian ini adalah kualitatif, dengan berusaha menggambarkan fenomena secara natural berdasarkan setting sosial apa adanya. Hasil penelitian ini menggambarkan di antaranya: a) musik Karinding memiliki nilai, Yakin, Sabar, Sadar. Sebagai pesan universal musik mereka. b) mencintai seni adalah mencintai kemanusiaan. Artinya, karya musik bukan diciptakan untuk kepentingan pasar sebagaimana mindstream musik saat ini, tetapi untuk mengembangkan manusia yang lebih konstruktif.
\end{abstract}

Kata Kunci: musik tradisional, Karinding, kemanusiaan

\section{PENDAHULUAN}

Seni untuk seni dan seni untuk kesadaran, adalah dua konsep yang dikemukakan oleh Plekhanov (2007: 1). Dua konsep ini selalu mengalami perdebatan berkenaan dengan kegunaan seni. Seni untuk seni menekankan bahwa, tujuan seni hanyalah menggambarkan tentang keindahan semata dan bukan untuk hal lain. Sedangkan seni untuk kesadaran merupakan konsep yang menempatkan bahwa seni yang indah adalah seni yang bersumber dari realitas sosial dan untuk membuka kesadaran sosial. Bertolak dari konsep yang kedua, sejatinya seni memiliki kegunaan untuk memberi kesadaran atas realitas sosial. Perspektif kritis sebagaimana Plekhanov, lebihbanyakberasumsibahwamasyarakat tidak diciptakan untuk seniman, tetapi seniman untuk masyarakat. Sehingga fungsi seni adalah untuk membantu perkembangan kesadaran manusia, membantu memajukan sistem sosial. Bagi kelompok yang ini seni tidak hanya memproduksi kehidupan, melainkan menjelaskannya bahwa hasil-hasil seni acapkali mempunyai tujuan untuk melakukan penilaian atas gejala-gejala kehidupan.

Berkaitan dengan dua kegunaan seni di atas, penting dipahami di era global seperti dewasa ini. Banyak ilmuan dan praktisi ragu dan cenderung sinis terhadap produk budaya global. Persoalan yang krusial dan sulit dihindari yakni, masalah eksistensi kebudayaan daerah. Salah satunya adalah terjadinya penurunan perhatian terhadap kebudayaan daerah yang merupakan jati diri suatu bangsa, erosi nilai-nilai budaya, terjadinya akulturasi budaya yang selanjutnya berkembang menjadi budaya massa (Suneki, 2012: 309). 
Budaya daerah dipercaya sebagai warisan leluhur yang terkandung nilainilaikearifanlokal.Iamenjadiidentitasdan martabat bagi suatu bangsa. Pemerintah Indonesia sendiri telah mengeluarkan regulasi melalui Permendikbud No. 10 Tahun 2014 berkenaan dengan pelestarian budaya tradisional. Namun, sepertinya hegemoni globabalisme telah menggiring generasi muda memaknai bahwa manusia modern adalah manusia yang mengikuti apa yang sedang berkembang, dan karenanya budaya tradisional pelan-pelan mulai memudar di kalangan generasi muda. Sebagaimana dikemukakan oleh Adorno bahwa di era modernitas berkembang pula industri budaya yang merupakan sebutan untuk industrialisasi dan komersialisasi budaya di bawah hubungan produksi kapitalis (Reksa, 2015: 95). Di dalam industri kapitalis, penciptaan budaya mengikuti tren produksi barang, sehingga karya seni seperti musik menjadi alat menciptaan branding dan simbol kebaruan.

Dengan demikian apa yang diharapkan oleh Plekhanov (2007) berkenaan dengan seni untuk kesadaran sosial menghadapi jalan yang terjal, produk kesenian semakin berubah dan berorientasikan pada keinginan pasar, sehingga pada akhirnya pekerja seni membuat karya didasarkan atas trend apa yang sedang booming agar karya mereka dapat laku di pasaran. Akhirnya, karya tersebut bukanlah berbentuk seni untuk seni apalagi seni untuk kesadaran. Lebih daripada itu, semacam ada stigmatisasi terhadap produk budaya tradisional sebagai sesuatu yang tidak bernilai prestise terutama di kalangan generasi muda.
Namun, di tengah keraguan dan dominasi pasar terhadap produk seni, masih ada pekerja dan pecinta seni yang berkarya untuk tujuan penyadaran sosial. Adalah komunitas pecinta kebudayaan Karinding yang berasal dari kampung Jaha, Balaraja, Kabupaten Tangerang, yang menyatukan diri menjadi satu grup musik bernama Barak Karinding. Karinding adalah alat musik tradisional khas Sunda. Karya komunitas Barak Karinding merupakan karya yang terinspirasi atas realitas sosial yang ada di sekitar lingkungan mereka. Mereka dengan semangat awi sajengkal-nya selalu menggaungkan kebudayaan Karinding dalam setiap acara pagelaran seni baik lokal maupun internasional, seperti Konferensi Asia Afrika di Bandung pada tahun 2015. Barak Karinding hadir layaknya antitesa atas industri budaya yangada, mereka mencoba menghadirkan konsep seni untuk kesadaran sosial.

Ada filosofi yang bisa disebut sebagai kearifan lokal pada komunitas Karinding, yakni: yakin, sabar, dan sadar. Tentu pesan ini terkait langsung dengan identitas budaya sebagai gambaran diri dan kelompok masyarakat di sekitar mereka pada umumnya. Maka, dapat pula dikatakan pesan-pesan tersebut adalah suatu ungkapan mengajak, meyakinkan, menyadarkan, tentang keadaan tertentu yang ada di sekeliling mereka. Dengan asumsi lain secara sosiologis, mereka bukan seniman yang mengabdi semata pada uang, tetapi mereka ingin karya seni yang mereka ciptakan adalah untuk kesadaran kolektif yang diharapkan memberikan dampak baik bagi masyarakat luas.

Berdasarkan masalah di atas, maka penting kiranya meneliti lebih mendalam 
tentang fenomena kesenian pada komunitas Barak Karinding tersebut. Beberapa hal yang penting diketahui sekaligus menjadi tujuan studi ini adalah: 1) bagaimana komunitas Barak Karinding memahami kesenian musik Karinding? 2) apakah ada nilai-nilai cinta kemanusiaan dan kebudayaannya?

\section{KERANGKA BERPIKIR Seni Mencintai Kemanusiaan}

Seorang ilmuan sosial kontemporer, Erich Fromm mengkaji kecendrungan psikologis masyarakat modern, yang menurut kajiannya memiliki hubungan dengan selera pasar kapitalisme. Bukan hanya life style sebagaimana memang digelisahkan banyak sosiolog generasinya, tetapi juga soal cinta pada kemanusiaan. Dalam karyanya "The Art of Loving, (1956)", ia mengkritik cintanya manusia modern. Cinta yang dimaksud yang berkaitan erat dengan studi ini adalah logika untung rugi. Seseorang menyukai dan ingin memiliki sesuatu ketika dapat menghasilkan dan menguntungkan secara materi. Sama seperti produksi massal modern yang mensyaratkan standardisasi komoditas, maka proses sosial juga mensyaratkan standardisasi. Tidak terkecuali juga produk-produk yang diciptakan manusia, ia mengikuti standar. Seperti halnya karya seni, musik misalnya, ia mengikuti tren yang sebenarnya tidak lahir dari dirinya sendiri, tetapi dirancang oleh kekuatan besar, yang bernama pasar kapitalisme. Dengan demikian manusia kontemporer akan merasa dirinya setara, jika memenuhi ekspektasi tren, dan karya atau produknya laku dan bernilai ekonomis.
Karakter manusia modern semacam diarahkan untuk bertukar dan menerima, untuk barter dan konsumsi, segalanya, spiritual maupun benda-benda material, menjadi sebuah objek pertukaran dan konsumsi, situasi sejauh menyangkut cinta sesama manusia sesuai dengan kebutuhan, sampai dengan karakter sosial manusia modern, tidak bisa mencintai, mereka dapat menukarkan "paket kepribadian" mereka dan berharap untuk adil. Tawar-menawar mengenai kepuasan (Fromm, 1956: 87).

Aspek praktis cinta kemanusiaan yang dikemukakan Fromm adalah cinta itu aktif dan bukan pasif, berdedikasi bukan sebatas menerima dan pamrih. Maka cinta itu sejatinya memberi. Sampai pada titik ini cinta acapkali dipahami secara keliru. Banyak orang menafsirkan hal ini dengan memaknai cinta sebagai "berserah diri", yaitu pengorbanan suci, atau keadaan yg terlepas dari sesuatu. Mereka acapkali juga merasa bahwa cinta merampas kebebasannya sebagai individu.

Fromm ingin mengkritik bahwa pemahaman seperti itu tidak benar, paling tidak untuk alasan bahwa cinta tidak terbatas memberi dalam bentuk materi. Atau mencintai karena berharap mendatangkan nilai materiil. Aspek yang paling penting dari memberi adalah kita memberikan diri kita sendiri, kehidupan kita, kesenangan kita, penderitaan kita, minat kita, pengetahuan kita, pengertian kita, dan keperdulian kita. Lalu kemudian memberikan diri kita sendiri dalam mencintai, sebagaimana orang takutkan, bukan berarti mengorbankan kebebasan kita sebagai individu. Apa yang mesti kita hilangkan adalah, keegoisan diri, yakni segala sesuatu yang hanya berpusat pada 
diri sendiri. Kita harus menghilangkan ego kita agar bisa menggapai jiwa kita.

Memahamikonsepcintakemanusiaan sebagaimana yang dikemukakan Fromm sesungguhnya, segala karya dan produk yang diciptakan manusia haruslah diarahkan kepada pertumbuhan dan perkembangan kemanusiaan itu sendiri. Bahwa hasrat dari segala sesuatu yang diciptakan manusia modern kini orientasinya bukan kepada manusianya, tetapi cinta, kalau tidak mau dikatakan egoisme, adalah hanya memusatkan pada nilai keuntungan. Padahal ada nilai yang autentik dari sebuah karya, ia harus ditujukan pada pembangunan dan eksistensi manusia. Karya musik jika mengikuti kerangka berpikir Fromm, hanyalah alat untuk memberi arti tentang eksistensi manusia. Eksistensi yang paling aktual pada manusia, ketika ia mampu memberi cinta pada yang bernilai kemanusiaan. Sebab tidak ada suatu produk manusia, apalagi seni, yang keluar dari dimensi manusia. Hanya saja persoalannya saat ini, karyakarya tersebut menghubungkan antara manusia dengan manusia lainnya hanya untuk kemanfaatan materiil dan manusia sebagai penciptanya, menjadi tujuan kedua. Dengan demikian, konsep ini perlu dibawa untuk membaca realitas seni musik Karinding pada komunitas Barak Karinding sebagai representasi musik tradisional Banten.

\section{Fetisisme Budaya}

Teori industri budaya memulai titik awal sudut pandangnya pada sistem kapitalis. Teori ini meminta kita untuk lebih kritis terhadap produk-produk budaya yang beredar kini, karena ada hidden ideology berupa bisnis budaya dalam produk kesenian (Arviani, 2013: 135). Dan fetisisme menjadi salah satu konsep yang menjadi perhatian Adorno. Sebagai salah satu tokoh penggagas teori kritis Mazhab Frankfurt, ia mengamati bahwa, pengabdi seni saat ini mengalami krisis, ia bukan lagi mengabdi pada seni yang memiliki nilai-nilai luhur, tetapi telah mendistorsi dirinya untuk pasar kapitalisme. Ia menyebut produk seni di bawah pasar kapitalisme berubah menjadi fetisisme budaya.

Fetisime adalah bentuk pemujaan terhadap produk tertentu. Dalam hal ini seni musik, memiliki nilai pengkultusan dalam dunia industri. Namun pasar menciptakan simbol-simbol tertentu, sehingga melalui industri budaya, manusia dibuat seolah-olah mati suri hingga terjebak dalam arus fetisisme komoditas (Adorno dan Horkheimer, 2002: 128).

Industri budaya menjadikan pekerja seni teralienasi dari dirinya, dalam arti ia asing dari karyanya sendiri. Seni berubah menjadi status dalam komoditas pasar. Baik pekerja seni dan penikmat seni telah dipaksa berpartisipasi aktif untuk mengikuti produk budaya massa. Sebagai balasannya, mereka akan mendapatkan kepuasan dan kebanggaan. Namun, tanpa disadari pada saat itulah mereka hanya mengalami kesadaran palsu. Manusia dijebak dan dikurung dalam lingkaran pemujaan sehingga mereka menjadi pasif, lemah, dan rentan terhadap manipulasi dan eksploitasi. Hal tersebut merupakan keberhasilan konspirasi kapitalisme lewat budaya populer (Hardiman, 2003: 34).

Masyarakat sebagai konsumen industri budaya mendapat pengaruh yang sering kali berada di luar nalar. 
Masyarakat menikmati suatu produk budaya sebagai representasi kehidupan nyata. Melalui produk budaya yang ditayangkan, masyarakat bisa merasakan emosi dan empati yang sama sehingga masyarakat menjadi penonton yang kehilangan nalar kritisnya. Bahkan kebanyakan warga masyarakat terhanyut dalam euforia. Mereka terjebak dalam fanatisme yang berlebihan terhadap suatu karakter atau tokoh yang diproduksi oleh budaya industri. Beberapa di antaranya juga menghabiskan waktu luangnya demi menikmati produk-produk industri budaya tersebut. Melalui anti-tesisnya terhadap pencerahan, Adorno berharap kesadaran masyarakat dapat tumbuh dan kembali kepada kemandirian akal budi. Hal tersebut dapat dilakukan melalui resistensi terhadap kapitalisme meskipun sangat minim tingkat keberhasilannya. Seharusnya, lanjut Adorno, kekuatan resistensi terhadap kapitalisme berada di dalam seni, khususnya seni modernis avant-garde. Bagi Adorno, seni di satu sisi merupakan fakta sosial, tetapi di sisi lain ia juga bersifat otonom dari masyarakat. Dengan kata lain, pada satu sisi seni dipengaruhi oleh masyarakat. Akan tetapi, pada sisi lain, ia bersifat independen.

Jalan keluar dari fetisime ini menurut Adorno bahwa manusia harus menjadi subjek otonom atas produknya sendiri. Dimana nilai-nilai estetika adalah landasan dalam seni agar produk kesenian tidak asing dari dirinya sendiri. Maka kesenian adalah membebaskan dan menyadarkan akan kondisi riil kehidupan manusia yang sesungguhnya.

\section{METODOLOGI PENELITIAN}

Penelitian ini menggunakan metode penelitian kualitatif. Penelitian kualitatif merupakan penelitian yang menghasilkan data deskriptif mengenai kata-kata lisan maupun tertulis, dan tingkah laku yang dapat diamati dari orang-orang yang diteliti. Metode ini menghendaki pelaksanaan penelitian berdasarkan pada situasi wajar (natural setting) sehingga orang kerap juga menyebutnya sebagai metode naturalistik (Idrus, 2000: 23).

Adapun teknik pengumpulan data dilakukan melalui tiga prosedur, yakni wawancara, observasi, dan dokumentasi. Hasil wawancara dan observasi dimasukkan sebagai data primer atau sumber utama penelitian, sementara data sekundernya adalah dokumen dapat berupa jurnal, majalah, buku, dan laporan lainnya yang berkaitan dengan topik penelitian.

Dalam menentukan informan digunakan teknik purposive sampling. Teknik ini biasa dipakai dalam penelitian kualitatif, dengan asumsi bahwa subjek penelitian telah diketahui dengan baik dan dianggap dapat menjawab permasalahan penelitian, dalam hal ini adalah semua personil komunitas Barak Karinding. Sifat wawancara adalah dialog langsung dengan informan, sehingga dapat dikatakan model ini adalah wawancara tidak terstruktur. Adapun observasi bersifat semi terstruktur, yakni peneliti mengikuti kegiatan tertentu yang berkaitan dengan penelitian. Peneliti juga dapat ambil bagian dalam kegiatan selama observasi namun tidak kontinu (Sugiyono, 2014: 225).

Setelah semua data terkumpul, selanjutnya dilakukan analisis mengikuti prosedur antara lain: pengumpulan 
data, reduksi data, penyajian data, dan penarikan kesimpulan atau verifikasi data.

\section{PEMBAHASAN}

\section{Kecintaan Komunitas Barak Karinding Terhadap Budaya Tradisional}

Karinding adalah alat musik yang berasal dari Sunda, terdapat di beberapa daerah Jawa Barat dan Banten. Ada dua bahan yang biasa digunakan sebagai bahan dasar, ialah pelepah kawung dan bambu. Untuk memainkannya Karinding dilekatkan di bibir kemudian ditepuk pelan agar tercipta resonansi suara. Berdasarkan cerita yang berkembang di masyarakat Sunda, pada mulanya, Karinding digunakan oleh para petani untuk mengusir hama karena suara dari Karinding menyerupai suara hewan seperti belalang, jangkrik, dan sejenisnya. Dalam perkembangannya, menjadi alat musik tradisional. Jika dimainkan secara bersama-sama atau dikolaborasikan dengan alat musik lain seperti seruling maupun angklung akan menghasilkan irama lembut dan khas.

Karinding adalah alat musik tradisional dan sangat sederhana namun memiliki makna filosofi yang belum sepenuhnya diketahui oleh genarasi saat ini terutama masyarakat Sunda khususnya. Ada sejumlah generasi muda yang sedang berupaya melestarikannya. Mereka tergabung dalam komunitas Barak Karinding. Dimulai sejak tahun 2011, tepatnya di kampung Jaha Balaraja, Tangerang. Komunitas ini dipelopori oleh Ahmad Lamhatun Nadzhori yang akrab disapa Ncek, bersama kawankawannya yang berprofesi sebagai seniman jalanan, yakni Muklis, Rita,
Johan dan Yopi. Mereka membulatkan tekad untuk membuat suatu pedepokan seni Karinding.

Dalam menarik minat masyarakat yang awam akan kebudayaan Karinding, Ncek memulainya dengan sering memainkan Karinding di berbagai tempat seperti mushola, masjid, saung, pos ronda, hingga tempat nongkrong pemuda pemudi Kampung Jaha. Bentuk Karinding yang hanya sejengkal tangan dan suara Karinding yang unik serta low decible ini menarik perhatian masyarakat untuk kemudian memainkannya.

Tahun 2014 barulah Barak Karinding aktif berkarya dan mulai mendapat banyak anggota serta sarana dan prasarana. Dalam mengembangkan kebudayaan Karinding, Barak Karinding membuat musik Karinding yang dipadukan dengan alat musik bambu lain seperti suling, kecapi, celempung, bambu air, gleger, songsoe, goong tiup, kepiar. Serta tak lupa diwarnai dengan sentuhan jimbe dan gitar. Langkah Barak Karinding dalam melestarikan kebudayaan Karinding dimulai dengan pementasan-pementasan agar khalayak luas dapat mengetahui bagaimana seni budaya Karinding ini. Dalam pementasan Barak Karinding menggunakan atribut tradisional untuk mengentalkan karakter budayanya seperti menggunakan iket kepala, baju pangsi, lomar baduy, lomar putih atau lomar hitam, celana pangsi putih atau hitam, sarung polos berwarna putih atau hitam, kain tenun atau kain batik yang dipakai oleh para anggota Barak Karinding ketika pementasan. Sehingga kemudian Barak Karinding hadir dengan konsep tradisional mulai dari musik hingga pada saat pementasan yang menggunakan baju khas sunda. 
Penampilan Barak Karinding yang mengusung jenis musik kontemporer dengan paduan alat musik tradisional serta atribut tradisional di tengah gempuran arus moderitas ini merupakan upaya perlawanan yang hendak Barak Karinding sampaikan atas trend yang mengungkung musik yang katanya harus modern dan kekinian. Bahkan lagu yang dibawakan oleh Barak Karinding lebih banyak yang bertemakan kesadaran sosial dan kritik atas realitas yang terjadi dewasa ini. Apa yang ditampilkan oleh Barak Karinding ini bukan tanpa alasan.

Dalam setiap aktivitasnya anggota Barak Karinding berpegang teguh pada filosofi Karinding yakni yakin, sabar, dan sadar yang terus disosialisasikan oleh anggota komunitas Barak Karinding, khususnya pada intern Barak Karinding terlebih dahulu.

Filosofi yakin, sabar, dan sadar ini merupakan filosofi yang dipelopori oleh Bah Olot. Filosofi pada awalnya merupakan filosofi dalam bermain Karinding(Daryana,2016:178).Kemudian Barak Karinding mengembangkan filosofi tadi menjadi filosofi hidup yang harus terejewantahkan dalam kehidupan sehari-hari. Filosofi yakin oleh Barak Karinding diilhami sebagai suatu filosofi yang berkaitan pada kaidah keIslaman dan keimanan, berawal dari dua kalimat syahadat dalam agama Islam kemudian dikembangkan lagi sebagai upaya untuk mendirikan keIslaman dan memahami rukun Islam dan rukun iman.

Keyakinan inijuga bagai pembuka diri terhadap segala potensi yang ada dalam diri sebagaimana filosofi dalam bermain Karinding. Sedangkan filosofi sabar oleh Barak Karinding sendiri diilhami sebagai filosofi untuk memperkuat generasi muda menghadapi zaman dengan segala perkembangannya. Filosofi sabar ini lebih mengacu pada Quran dan para ulama, seperti "sesungguhnya Allah bersama dengan orang-orang yang sabar", lalu "sabar itu adalah kehendak Allah, sabar itu dibawah takdirnya Allah". Maka makna sabar ini pun dapat diartikan sebagai suatu sikap ketahanan diri atas segala situasi yang terjadi pada diri manusia, karena manusia diciptakan dengan hawa nafsu maka kemudian sifat sabar ini akan menjadi mulia jika dapat mengimplementasikannya. Filosofi selanjutnya yakni sadar, dimana Barak Karinding mengilhami filosofi ini sebagi filosofi yang berkaitan dengan lima perkara yang tidak boleh dilakukan oleh pemain Karinding. Adapun lima perkara yang dimaksud adalah tidak boleh mabuk-mabukan, tidak boleh bermain wanita, tidak boleh mencuri, tidak boleh berjudi dan tidak boleh membunuh. Filosofi sadar ini tak terlepas dari filosofi yakin bahwa ada Dzat Yang Maha Kuasa penguasa semesta karena manusia yang tidak mengindahkan adanya Ilahi dalam setiap langkah mereka pada akhirnya hanya akan memiliki kesadaran yang menyesatkan dan definisi hidup yang pincang tak selaras dengan nilai-nilai luhur yang ada.

Atas dasar filosofi inilah kemudian Barak Karinding mengembangkan karya seni dan kiprahnya dalam berkarya karena yang dicari oleh Barak Karinding bukanlah keuntungan, namun bagaimana Barak Karinding dapat dijadikan sebagai alat musik yang hidup di tengah-tengah imperialisme budaya kontemporer. Mengingat dulu Karinding berfungsi sebagai alat musik pergaulan dan alat musik yang digunakan untuk 
dakwah. Penghayatan atas filosofi yakin, sabar, dan sadar yang tersosialisasikan dengan baik, membuat Barak Karinding memberikan kehidupan seninya untuk memberikan kesadaran atas kondisi yang ada serta menyebarkan nilai-nilai kebudayaan yakin, sabar, dan sadar pada semua yang mendengarkan.

Bagi mereka, mencintai kesenian musik tradisional berarti adalah memberikan apa yang dimiliki oleh individu dan menjadikan individu tersebut produktif dengan tetap menjadi subjek seni. Barak Karinding sejauh ini memberikan dedikasinya pada pementasan-pementasan karya seni dan berusaha menginspirasi melalui musik tradisional, tak menghiraukan keuntungan materil apa yang didapat namun, sejauh mana Barak Karinding mampu menyiarkan nilai-nilai luhur budaya pada seluruh penikmat musik. Barak Karinding secara konsisten mengimplementasikan nilai yakin, sabar dan sadar. Atas dasar kecintaan pada kebudayaan Karinding pun Barak Karinding telah berhasil menciptakan beberapa karya di antaranya lagu Wilungan Cisadae, Air, Hukum Alam, Gemilanglah Tangerang, Balaraja Penuh Histori, Pesona Banten dan Kota Seribu Mimpi.

Karya yang diciptakan Barak Karinding jauh dari kesan budaya populer yang mengikuti selera pasar. Barak Karinding dalam penciptaan karyanya bersumber pada realitas seharihari dan berusaha membawa pesan yang dapat meningkat kebersamaan. Sehingga apa yang dikatakan Adorno bahwa industri budaya menjadikan pekerja seni teralienasi dari dirinya, tak nampak pada musik Barak Karinding. Nilai filosofi yang dipegang teguh tadi menguatkan Barak Karinding sebagai seniman yang tidak terbawa oleh arus fetisisme.

Dengan filosofi yakin tadi Barak Karinding memegang teguh bahwa keyakinan juga diartikan sebagai pembuka diri terhadap segala potensi yang ada, sehingga hal itu pun menjadi energi positif dimana Barak Karinding mulai mencari tahu bagaimana keberhasilan yang ingin diraih dapat dicapai, menyusun langkah yang diyakini benar untuk hidup yang lebih baik dengan tidak terlepas akan keyakinan dan bertawakal kepada kehadirat-Nya. Atas keyakinan bahwa ada Dzat yang berkuasa atas alam semesta ini kemudian dari keyakinan ini diharapkan memiliki sifat yang sederhana dalam kerendahan hati.

Jika mengacu pada perspektif Fromm, hal ini dapat dikatakan bahwa mencintai seni musik sesungguhnya tujuannya bukan hanya pada musik itu sendiri, tetapi kepada manusia penikmat musik dan mendorong manusia lebih produktif menjalani kehidupan sehari-hari. Filosofi dalam musik Karinding membuka potensi diri manusia ke arah yang lebih konstruktif. Sebagai contoh riil adalah filosofi sabar, dimaknai sebagai suatu sikap ketahanan diri atas segala situasi yang terjadi pada diri manusia, karena manusia diciptakan dengan hawa nafsu, maka sifat sabar ini akan menjadi mulia jika dapat mengimplementasikannya. Serta filosofi sadar yang membuat Barak Karinding menyadari bahwa dirinya bukan siapa-siapa di semesta ini. Ketika mencoba hidup dengan ketahanan diri maka akan memiliki kesadaran sebagimana yang diharapkan selaras 
dengan nilai-nilai luhur agama, budaya dan sosial serta hukum yang ada.

Dua filosofi ini menguatkan Barak Karinding untuk tidak terjebak dalam fetisisme budaya dan tertelan arus industri budaya. Karena sebagaimana yang dianjurkan oleh ilmuan sosial kritis, bahwa jalan keluar dari fetisisme tadi adalah kerja seni harus bertujuan untuk membuat artefak-artefak atau musik yang berguna bagi manusia. Dengan filosofi sabar yang diejawantahkan dalam ketahanan diridengan bersandarkan pada filosofi keyakinan yang menggambarkan kecintaan pada Allah, maka dalam berkarya Barak Karinding menahan untuk tidak terjermus mengikuti trend musik yang hanya berisikan kepuasan semu semata.

Dengan demikian kecintaan Barak Karinding didasarkan atas kecintaannya yang tumbuh melalui implementasi nilai-nilai filosofis dalam kebudayaan Karinding sehingga menjadi pagar bagi Barak Karinding untuk menghadapi arus modernisasi. Barak Karinding dengan berpegang teguh pada nilai-nilai filosofisnya menjadikan dirinya sebagai subjek yang utuh dalam berkarya di dunia seni.

\section{Konstruksi Pemikiran Barak Karinding dalam Pembuatan Karya}

Beberapa pekerja seni dalam membuat karya biasanya mendapat berbagai inspirasi sebelum dituangkan dalam sebuah karya seni seperti lagu, misalnya. Namun era modernitas ini membawa pekerja seni khususnya seniman musik untuk menciptakan karya atas dasar keinginan pasar karena mengharapkan karyanya dapat menjual dan mendatangkan keuntungan. Hanya segelintir seniman musik yang tergugah untuk menciptakan karya yang bertujuan pada penyadaran sosial. Barak Karinding mencoba untuk menghasilkan karya-karya yang dapat membuka kesadaran, bukan hanya tentang nilainilai yang bersifat teologis, tetapi tentang pentingnya menjaga lingkungan dan menjaga nilai-nilai moral yang ada di tengah masyarakat.

Barak Karinding memang memiliki tujuan untuk menciptakan karya yang membuka pemikiran masyarakat dan memberikan kesenangan dalam hal yang positif atas segala yang terjadi dalam dirinya. Barak Karinding tidak berminat membuat karya yang justru menambah suasana hati menjadi semakin tak menentu atau menurut istilah kekinian adalah suasana 'galau'.

Tak tampak karya-karya Barak Karinding berorintasi mengejar target pasar.Seperti lagu karya Barak Karinding, yakni Walungan Cisadane diciptakan atas keprihatinan kondisi sungai Cisadane yang membentang di daerah Tangerang yang menjadi sumber kehidupan dan mulai tak terjaga kebersihannya. Sehingga kemudian muncul ide membuat lagu tersebut untuk menyadarkan pentingnya menjaga sungai untuk keberlangsungan ekosistem yang ada. Senada dengan Wilungan Cisadane ada pula lagu Air yang bertemakan menjaga lingkungan. Ada pula lagu berjudul Hukum Alam yang bercerita tentang keserakahan manusia dan kritik terhadap manusia. Selain itu ada juga lagu yang mengajak untuk mencintai daerah sendiri seperti lagu yang berjudul Balaraja Penuh Histori dan Pesona Banten. Serta ada pula lagu yang berisikan kritik atas kondisi sosial 
ekonomi di kota industri di Tangerang, dan lahirlah lagu Gemilanglah Tangerang dan Kota Seribu Mimpi.

Jika ditelisik bersama, bahwa setiap karya Barak Karinding merupakan karya yang bersumber atas gejala sosial yang ada dan bersumber dari problema masyarakat itu sendiri. Barak Karinding mengangkat hal-hal yang patut diperhatikan dalam konteks sosial, ekonomi, maupun politik agar disadari secara kolektif. Barak Karinding memilih kehidupan sosial sebagai sumber inspirasi dan bukanlah pasar komersil yang menjadi orientasi mereka.

Secara langsung maupun tidak Barak Karinding melawan fetisisme budaya karena Barak Karinding menjadi subjek yang utuh melalui penguatan diri atas nilai filosofis Karinding. Dengan demikian dapat dipahami bahwa konstruksi pemikiran dalam pembuatan karya Barak Karinding adalah nilai filosofis sebagai landasan. Dan juga sebagian banyak dari karya-karya mereka bersumber dari kehidupan sosial dan bertujuan mengedukasi masyarakat.

\section{PENUTUP}

Produk kesenian seharusnya adalah gambaran tentang diri dan sosial seorang pencipta seni. Ia tidak boleh tercerabut dari akarnya. Namun, dunia modern telah mereduksi kesenian untuk tujuan pasar, sehingga kesenian sulit melepaskan diri dari kepentingan-kepentingan ekonomi, bahkan juga politik. Pelaku seni sebagaimana dikritik dalam banyakkajian ilmu sosial postmodern sebagai orangorang yang tercerabut dari produknya sendiri. Mereka bukan mengabdi untuk seni, alih-alih untuk kesadaran sosial.
Tetapi mereka mengabdi untuk uang, sambil memanfaatkan kesenian seperti musik dan sejenisnya.

Komunitas Barak Karinding, sayupsayup terdengar, mereka gelisah dengan kesenian daerah yang mulai tergerus di generasi muda. Mereka menyadari mengikisnya kesenian daerah, berartijuga akan mengikis identitas mereka sendiri. Mereka mencintai seni, karena mencintai masyarakat di sekitar mereka agar tidak tercerabut dari akar budayanya. Kesenian musik sebagaimana Karinding, memberi pesan secara universal, untuk mengenal siapa diri budaya dan diri sosial mereka. Eksistensi komunitas Barak Karinding juga memberi pesan bagi para seniman agar jangan menciptakan karya seni yang melulu berorientasi materiil. Karena dengan begitu, mereka telah membiarkan karya seni yang asalnya memiliki nilai-nilai luhur digunakan untuk menciptakan ketidaksadaran sosial budaya, ekonomi dan politik dengan cara mengkomodifikasikan karya seni.

\section{DAFTAR PUSTAKA}

Reksa, Abdul. 2015. Tinjauan Buku Kritik Terhadap Modernitas. Jurnal Kajian Wilayah, Vol. 6 No. 1. Lembaga Ilmu Pengetahuan Indonesia.

Lamhatunnadzori, Ahmad. 2016. Terater Musik Kontemporer Barak Karinding (Bakkar) Sebagai Media Melestarikan Nilai-Nilai Budaya. Skripsi Fakultas Ilmu Sosial dan Ilmu Politik, Universitas Sultan Ageng Tirtayasa.

Fromm, Fromm. 1956. The Art Of Loving. New York: Harper \& Row.

Hardiman, Budi. 2003. Melampaui Positivisme dan Modernitas. Yogyakarta: Kanisius.

Arviani, Heidy. 2013. Budaya Global dalam Industri Budaya: Tinjauan 
Madzhab Frankfurt Terhadap Iklan, Pop Culture, dan Industri Hiburan. Jurnal Global \& Policy, Vol.1 No. 2. FISIP UPN “Veteran” Jawa Timur.

Daryana, Hinhin Agung. 2016. Pergeseran Fungsi Instrumen Karinding di Jawa Barat. Jurnal Pendidikan dan Kajian Seni Vol. 2, No. 2. Institut Seni Budaya Indonesia.

Idrus, Muhammad. 2009. Metode Penelitian Ilmu Sosial. Jakarta: Erlangga.

Horkheimer, Max \& Theodor W. Adorno. 2002. Dialektika Pencerahan. Terjemahan Ahmad Sahidah.
Yogyakarta: IRCiSoD.

Friesen, Norm, Carina Henriksson \& Tone Saevi. 2012. Hermeneutic Phenomenology in Education. New York: Sense Publishers.

Plekhanov, G. V. 2007. Seni dan Kehidupan Sosial. Terjemahan Samandjaja. London: Art Social Life.

Suneki, Sri. 2012. Dampak Globalisasi Terhadap Eksistensi Budaya Daerah. Jurnal Ilmiah CIVIS, Volume II, No 1.

Sugiyono. 2014. Metode Penelitian Kuantitatif, Kualitatif, dan RED. Bandung: Alfabeta. 